\title{
Un enfoque para la creación de contenido online interactivo
}

\section{An approach for developing interactive online content}

\author{
Daniel Pérez-Berenguer \\ Centro de Producción de Contenidos Digitales \\ Universidad Politécnica de Cartagena. España. \\ daniel.perez@upct.es \\ Jesús García-Molina \\ Departamento de Informática y Sistemas \\ Universidad de Murcia. España. \\ jmolina@um.es
}

\begin{abstract}
Resumen
Las universidades se enfrentan al reto de producir contenidos online interactivos para ser utilizados en cursos de los estudios reglados o como cursos masivos online (MOOC). La producción de estos contenidos requiere actualmente un gran esfuerzo de los docentes que deben dedicar una gran cantidad de tiempo. Por ello, las universidades deberán proporcionar recursos (herramientas, métodos, personal,..) que faciliten esta tarea a los docentes. En este sentido, el Centro de Producción de Contenidos Digitales de la Universidad Politécnica de Cartagena ha definido un enfoque que consiste de un proceso de producción y una infraestructura software que lo soporta. En este artículo se presenta el proceso que consta de varias etapas en las que intervienen diferentes roles como el docente, diseñador y programador web. El formato de presentación Web de los contenidos se basa en un conjunto de plantillas (esqueletos de código HTML5 y CSS) que son adaptadas para cada curso. Además se ha definido una plataforma que soporta la gamificación, de modo que los docentes pueden incluir juegos en sus cursos. Aunque el artículo no se centra en las cuestiones de implementación de la infraestructura que soporta el proceso, conviene destacar que se aplican SCORM y LTI para favorecer la integración en diferentes plataformas.
\end{abstract}

\section{Palabras clave}

Contenido online e interactivo, producción de contenido digital, MOOC, SCORM, LTI, gamificación, plataforma de aprendizaje

\begin{abstract}
Interactive online content production is one of the main challenges facing universities today. This content production is a task that requires a great deal of teachers' time and effort. Thus, universities should provide resources (e.g., software tools, methods and staff) aimed at facilitating this task. With this in mind, the Digital Content Production Centre of Cartagena Polytechnic University (Spain) has defined an approach which includes a content production process and software infrastructure to support it. This article describes the process, consisting of several stages to be carried out by different professionals (teachers, content designers and Web developers). Several templates (HTML5 and CSS code skeletons) have been created in order to establish the visual structure of the contents. These templates are intended to favor the reuse and they must be completed for a concrete use. In addition, a platform has been built to support gamification. Finally, it is worth noting that SCORM and LTI may be used to create cross-platform contents, although implementation issues will not be addressed in this article.
\end{abstract}

Keywords

Online and interactive content, digital content production, MOOC, SCORM, LTI, elearning platform. 


\section{1.- Introducción}

A finales del siglo pasado, el auge de Internet y la Web propició que emergiese la visión de un nuevo modelo de universidad en el que las nuevas tecnologías posibilitaban una modernización de sus métodos de enseñanza y una mejora de su financiación (Tsichritzis, 1999). Por un lado, las universidades podrían crear contenidos y hacerlos accesibles de forma online desde cualquier lugar del mundo. Esto podría ser una buena fuente de ingresos y daría lugar a una fuerte competitividad entre las universidades para conseguir alumnos interesados en su oferta. Por otro lado, los métodos tradicionales de enseñanza basados en clases presenciales podrían ser reemplazados por nuevos métodos basados en la existencia de contenidos online de calidad que estarían a disposición de los alumnos de las asignaturas de los estudios reglados.

En relación al cambio en los métodos tradicionales de enseñanza universitaria, otro factor que debe ser tenido en cuenta, además de las nuevas tecnologías, es el hecho de que los estudiantes que ahora llegan a las aulas universitarias han crecido en un mundo digital y no se sienten motivados por las clases presenciales. Su proceso de aprendizaje podría verse beneficiado por la existencia de contenidos didácticos online tales como vídeos, animaciones y actividades interactivas.

Con el paso de los años, las universidades están evolucionando en el sentido expuesto arriba, aunque con ritmos diferentes dependiendo de los países. La mayoría de universidades ya han implantado "aulas virtuales" basadas en plataformas de e-learning o LMS (por ejemplo Moodle o Sakai) las cuales proporcionan flexibilidad en el proceso educativo permitiendo romper las barreas geográficas y temporales. Sin embargo, en la enseñanza reglada sigue siendo todavía predominante la clase magistral y el "aula virtual" se utiliza como un repositorio del material usado en clase, pero escasea la producción de contenidos digitales dirigidos a que una parte del aprendizaje pueda ser online e interactivo.

Por otro lado, el año 2012 fue señalado por la revista The New York Times como "El año MOOC" $"$. El término MOOC (Massive Open Online Course) ha sido acuñado para hacer referencia a cursos que pueden ser seguidos online por cualquier persona interesada independientemente del lugar en el que se encuentre. A partir de 2012 se ha producido un auge de las plataformas MOOC y ha crecido considerablemente el interés por los MOOC. Han aparecido varias plataformas e-learning para la creación y acceso a MOOC, entre las que destacan Coursera ${ }^{2}$, edX $^{3}$, Udacity $^{4}$ y MiriadaX ${ }^{5}$ (Méndez García, 2013). Se han llevado a cabo estudios comparativos de diversas plataformas MOOC (Pereira, Sanz-Santamaría y Gutiérrez, 2015; Taneja y Goel, 2014) que analizan sus principales características. Realmente, los MOOC son un tipo de contenido e-learning, aunque actualmente el término se utiliza para denotar cualquier contenido online, sin

\footnotetext{
1 http://www.nytimes.com/2012/11/04/education/edlife/massive-open-online-courses-are-multiplying-ata-rapid-pace.html?_r=0

${ }^{2}$ https://es.coursera.org/

${ }^{3}$ https://www.edx.org/

${ }^{4} \mathrm{https}: / /$ www.udacity.com/

${ }^{5} \mathrm{https}: / /$ miriadax.net/home
}

Un enfoque para la creación de contenido online interactivo en las instituciones universitarias. Daniel Pérez-Berenguer y Jesús García-Molina.

Página 2 de 24 
considerar si tiene todas las características que los definen, como se discute en (Zapata, 2014).

La producción de contenidos, sean destinados a MOOC o curso reglados, es una tarea compleja que implica actividades de diferente naturaleza, tales como crear elementos textuales y gráficos, grabar vídeos, o introducir preguntas de autoevaluación. Por ello, esta tarea requiere mucho tiempo y esfuerzo a los docentes. Por tanto, uno de los principales desafíos para implantar el nuevo modelo de universidad es la producción de contenidos online de calidad de forma eficaz. Abordar este desafío exige que las universidades dispongan de los recursos (por ejemplo, herramientas software) que faciliten la creación de contenidos y del personal cualificado que apoye al profesorado interesado en la creación de contenidos, así como que se definan procesos que permitan abordar esta actividad de una forma sistemática y eficiente, con el fin de reducir costes. En este sentido, la Universidad Politécnica de Cartagena (UPCT) ha creado el Centro de Producción de Contenidos Digitales (CPCD).

En este artículo se presentará el proceso de producción de contenidos definido en el CDCD/UPCT por el primer autor y cuya automatización está siendo abordada en su tesis doctoral. El objetivo de este proceso es facilitar la creación de contenidos a los docentes reduciendo el esfuerzo y el tiempo que necesitan dedicar para conseguir contenidos de alta calidad. El proceso es soportado por una plataforma software y ya ha sido aplicado para la producción de varios cursos: "Gestión de los Recursos Humanos", del Grado de Administración y Dirección de Empresas y en el Proyecto ACADIA ${ }^{7}$ (African Center for Applicative Development \& Innovation in Agribusiness) un proyecto europeo que la UPCT lidera. Mientras que este artículo se centra en la descripción detallada de las etapas del proceso y en el diseño Web de los contenidos, los resultados obtenidos de la evaluación del proceso serán publicados en un próximo artículo en esta revista. Para ello, se elaborará una encuesta destinada a que los docentes que hayan creado algún curso evalúen el proceso después haber sido seguido por los estudiantes; también se presentarán los tiempos dedicados por cada rol en cada etapa del proceso. Cabe destacar que en el presente artículo también se presenta el componente de gamificación que incluye la plataforma que soporta el proceso.

Acabamos esta primera sección comentando la organización del resto del artículo. Primero se motivará el trabajo realizado y se ofrecerá una visión general del enfoque global del que forma parte el proceso presentado. Entonces se describirán las diferentes etapas del proceso y los roles involucrados. A continuación se explicará el formato Web definido para la presentación de los contenidos el cual está basado en el uso de un banco de plantillas HTML5 y CSS para favorecer la calidad y reutilización. Luego se presentará el componente creado para soportar la gamificación, y un ejemplo de juego creado. Finalmente se extraen algunas conclusiones adquiridas de la experiencia de producción de varios cursos. Cabe destacar que este proceso es soportado por una infraestructura software cuya implementación no es tratada en este artículo.

\footnotetext{
${ }^{6}$ http://forma.upct.es/course/view.php?id=3

${ }^{7}$ http://forma.upct.es/course/view.php?id=4
}

Un enfoque para la creación de contenido online interactivo en las instituciones universitarias. Daniel Pérez-Berenguer y Jesús García-Molina.

Página 3 de 24 


\section{2.- Motivación}

Los sistemas LMS (Learning Management System) son las plataformas e-learning más utilizadas en las universidades. Ellos permiten la gestión y organización de los cursos proporcionando soporte para la gestión de usuarios, seguimiento y evaluación de los cursos, entre otras funcionalidades básicas. Las plataformas MOOC que han aparecido recientemente son un tipo de plataforma e-learning que permiten el desarrollo de cursos que cumplen con unas características particulares (Castaño y Cabero, 2013): online, masivos, gratuitos, sin criterios de admisión, con mecanismos de evaluación, con fechas de comienzo y finalización y con cierta semejanza con una clase. Los MOOC pueden también ser desarrollados con plataformas LMS extendidas con algunas características, como la capacidad de manejar la naturaleza masiva, la evaluación por pares y autoevaluación, o la incorporación de herramientas colaborativas en la red. De hecho, un LMS muy extendido como Moodle ha sido recientemente extendido para alojar MOOCs.

Las plataformas LMS y MOOC no suministran herramientas para la creación de contenidos (Boneau, 2007) salvo un editor de código HTML que permite insertar texto o imágenes con opciones de edición básicas como el uso de negritas o cursivas. Las herramientas de autor de e-learning (e-learning authoring tools) como eXeLearning ${ }^{8}$ y Easygenerator $^{9}$ son las que realmente están destinadas a la creación de contenidos.

El contenido que se encuentra en las plataformas LMS está formado principalmente por documentos, vídeos y enlaces de interés. Tanto los documentos como los vídeos son creados normalmente por el docente usando herramientas externas como procesadores de texto o sistemas de grabación audiovisual. Por otro lado, el contenido de los cursos MOOC suele estar basado principalmente en vídeos combinados con preguntas de tipo test. Además, es habitual proporcionar espacios donde fomentar la comunicación entre los alumnos y plantear ejercicios de evaluación por pares que permitan manejar la naturaleza masiva de estos cursos.

Muchas universidades, tratando de facilitar la tarea de grabación del material audiovisual al docente así como pretendiendo que el material obtenido sea de mayor calidad, han creado aulas de grabación audiovisual donde los docentes pueden acudir a grabar sus vídeos, ya sean destinados a un curso reglado o un MOOC. A estas aulas se suelen aplicar tratamientos acústicos y tienen equipos de iluminación, micrófonos, cámaras, etc. Algunas universidades han llegado a convertir las aulas en las que se imparte docencia en aulas de grabación audiovisual, de modo que, tras finalizar la grabación, el vídeo es procesado y tras una verificación puede ser publicado para que el alumno pueda visualizarlo posteriormente tantas veces como quiera. El proyecto Opencast ${ }^{10}$ liderado por la Universidad de California en Berkeley ha puesto en marcha esta idea.

\footnotetext{
${ }^{8}$ http://exelearning.net/

${ }^{9} \mathrm{https}: / / \mathrm{www}$.easygenerator.com/

${ }^{10} \mathrm{http}: / / \mathrm{www} . o p e n c a s t . o r g /$
}

Un enfoque para la creación de contenido online interactivo en las instituciones universitarias. Daniel Pérez-Berenguer y Jesús García-Molina. 
Las universidades suelen elaborar y publicar guías que incluyen recomendaciones para crear contenidos y en las que se fijan los criterios que deben seguirse para la creación de cursos. También ponen a disposición de los docentes plataformas para la publicación de los cursos.

Un aspecto clave que debe estar presente en la elaboración de cursos alojados en plataformas e-learning es la posibilidad de reutilización del contenido entre diferentes plataformas. Diferentes estándares han ido apareciendo para solucionar este problema como IEEE LTSC (2016), IMS LD (IMS-GLC, 2016), SCORM (SCORM, 2016) o IMS LTI (Learning Tools Interoperability) (IMS-LTI, 2016). Por tanto, las universidades deberían fijar una estrategia para conseguir la interoperabilidad.

Como veremos en la siguiente sección, en nuestro caso hemos elegido SCORM y LTI. SCORM es el estándar más extendido y que cuenta con más soporte y además, combina muchas especificaciones como IMS, AICC y IEEE en un único modelo. Permite la definición de itinerarios de aprendizaje y define un empaquetado de los contenidos que permite su distribución. SCORM posibilita el seguimiento del aprendizaje de diferentes formas como la definición de objetivos o acumulando el tiempo empleado por el alumno sobre el objeto de aprendizaje. LTI establece una forma estándar para integrar aplicaciones de aprendizaje. LTI nos permite enlazar los cursos elaborados y publicados mediante el proceso definido en las siguientes secciones, con plataformas LMS y plataformas MOOCs. A diferencia de SCORM, LTI está soportado por las plataformas MOOC más extendidas como Coursera o edX (IMS-CPD, 2016).

A pesar de la existencia de plataformas, estudios de grabación y de las mencionadas guías, entre otras facilidades ofrecidas por las universidades, la tarea de producir contenidos online de calidad e interoperables requiere de un gran esfuerzo de los docentes, lo cual motiva un rechazo de la mayoría de ellos o que abandonen un proyecto de creación de un curso antes de su finalización. Para afrontar este problema, la UPCT ha creado el Centro de Producción de Contenidos Digitales (CPCD) como unidad encargada de apoyar a los docentes en la creación de contenidos online educativos. Este centro es responsable de proporcionar los recursos necesarios para esta tarea, en particular procesos y herramientas software para la creación y gestión de contenidos, así como personal de apoyo y salas de grabación. En la siguiente sección se describe la estrategia definida por el CPCD para la producción de contenidos.

\section{3.- Una estrategia para la producción de contenidos}

Ante el reto de definir una estrategia de producción de contenidos por parte del CPCD, se analizaron las plataformas e-learning (Coursera, edX, Udacity y Miríada X) y las herramientas de autor e-learning (eXeLearning, Ardora $7^{11}$, Cuadernia ${ }^{12}$, JCLIc ${ }^{13}$, CourseLab $^{14}$ y Easygenerator) más extendidas, así como numerosos cursos online y

\footnotetext{
${ }^{11} \mathrm{http}: / /$ webardora.net/index_cas.htm

12 http://cuadernia.educa.jccm.es/

${ }^{13} \mathrm{http}: / / \mathrm{clic} . x t e c . c a t / \mathrm{es} / \mathrm{jclic} /$

${ }^{14} \mathrm{http}: / /$ www.courselab.com/view_doc.html?mode=home
}

Un enfoque para la creación de contenido online interactivo en las instituciones universitarias. Daniel Pérez-Berenguer y Jesús García-Molina. 
MOOC creados recientemente. Este estudio previo permitió establecer las decisiones de diseño de nuestro enfoque.

Como expusimos al motivar nuestro trabajo, el principal objetivo de la estrategia que se ha definido es reducir el esfuerzo y tiempo necesarios para crear contenidos online interoperables de calidad, siendo conscientes de que la mayoría de docentes no tienen los conocimientos y destrezas necesarios para abordar la creación de dichos contenidos. También, desde un principio se marcó como objetivo facilitar la integración de los contenidos en diferentes plataformas LMS y MOOC aplicando los estándares disponibles. Para alcanzar estos objetivos se ha desarrollado una plataforma que integra varias herramientas software y se ha definido un proceso de producción de contenidos en el que el docente se ve apoyado por personal del CPCD en la creación de material online para sus cursos reglados o MOOC. En esta sección discutiremos las ideas que han guiado la construcción de la plataforma, mientras que las etapas y roles del proceso serán explicados con detalle en la siguiente sección.

En el estudio de las plataformas existentes observamos que aquellas que ofrecen soporte para la creación de contenidos lo hacen a través de un editor de código HTML, con la posibilidad de insertar código CSS o enlazar diferentes tipos de documentos o imágenes como en el caso de Google Course Builder a través de un editor tipo WYSIWYG (What You See Is What You Get). En general, no proporcionan funcionalidades que permitan agregar animaciones interactivas o efectos avanzados sobre el texto o imágenes que requieran desarrollo de código a medida. Por otro lado, las herramientas de autor analizadas presentan limitaciones como en el registro de la información de seguimiento (únicamente el tiempo invertido en las unidades de aprendizaje o su finalización) o en la interoperabilidad que ofrecen, limitada solo a plataformas LMS.

Para paliar las mencionadas limitaciones de las plataformas e-learning y herramientas de autor se ha desarrollado una plataforma denominada UPCTforma que integra una herramienta de autor de e-learning junto a componentes para la gamificación, gestión multimedia, seguimiento de actividades, evaluación, autenticación y despliegue de los contenidos. La herramienta de autor ofrece funcionalidad relacionada con algunos aspectos básicos en la creación de cursos online:

- Un conjunto predefinido de plantillas que integran diferentes formas de organizar el contenido así como diferentes efectos interactivos que pueden ser aplicados sobre el mismo.

- Animaciones interactivas que son programadas ad-hoc y que permiten al usuario interactuar con el contenido hasta completar la lógica de la animación consiguiendo una participación activa del mismo.

- Un conjunto predefinido de actividades.

- Un reproductor de vídeos enlazado a diferentes servidores de reproducción y con diferentes niveles de seguridad.

- Tres tipos de evaluaciones predefinidas.

- Diferentes tipos de juegos que pueden ser aplicados en la enseñanza online.

Un enfoque para la creación de contenido online interactivo en las instituciones universitarias. Daniel Pérez-Berenguer y Jesús García-Molina.

Página 6 de 24 
Se ha definido un formato para que la presentación Web de los contenidos se ajuste a los estándares de calidad actuales. Para proveer de este formato y para facilitar la reutilización se ha desarrollado un banco de plantillas. Cada plantilla define uno de los elementos visuales básicos a partir de los cuales se organiza el contenido. Cada plantilla establece una estructura visual basada en texto, imágenes, vídeos y animaciones interactivas, así como el uso de diferentes efectos. Por ejemplo, una de las plantillas establece dos columnas con texto o imágenes y otra tres columnas de imágenes que al ser pulsadas muestran una pantalla modal con texto. Nótese que el uso de las plantillas asegura la calidad de la presentación y la reutilización. Una plantilla es un esqueleto de código HTML5 y CSS con "huecos" que deben ser completados cada vez que es usada para indicar el texto, imágenes, vídeos o animaciones concretas que correspondan. El formato Web de los contenidos basado en plantillas se explicará en la quinta sección de este artículo. Más detalle sobre estos recursos será proporcionado en las secciones "Organización de los Contenidos" y "Gamificación”.

En el análisis de cursos online, en particular MOOC, que hemos llevado a cabo se observa que el vídeo es el principal elemento usado para presentar el contenido y esto ocasiona serias dificultades para conseguir contenidos atractivos y didácticos, entre los que nosotros destacaríamos los siguientes:

- El docente invierte una parte importante de su tiempo en realizar el guion del vídeo.

- El docente necesita un periodo de adaptación a los medios audiovisuales, dado que debe ser grabado en salas multimedia con varios focos de luz, una cámara y elementos de sonido a su alrededor.

- En muchos casos no se respeta la regla de utilizar vídeos de corta duración. Se generan vídeos que son una transcripción de una clase real. Cuando un alumno se enfrenta a un vídeo de larga duración experimenta un rechazo al mismo.

- Por regla general es necesario la edición del vídeo y procesado (rendering) por parte del técnico de audiovisuales lo que encarece el coste de desarrollo del contenido online.

- Mantener actualizados los cursos es costoso. La modificación de un vídeo requiere que intervenga el técnico audiovisual para realizar su edición y su posterior procesado.

- No existe un medio de indexación, almacenamiento y puesta en línea automatizado. En estos casos, el técnico de audiovisuales obtiene el fichero "mp4" tras el procesado, lo sube al servidor de streaming y pasa el enlace al docente. A su vez, el docente incluye el enlace en la plataforma e-learning.

Por tanto, el formato de cursos basados principalmente en vídeo, que es empleado habitualmente, supone un coste elevado para una institución universitaria que mantenga una gran producción de contenidos online, y además no está demostrado su valor desde un punto de vista didáctico (Anna Hansch et al., 2015). Para abordar estos problemas, tanto el proceso que proponemos como las plantillas creadas están dirigidos a presentar el contenido de diferentes formas combinando el uso de vídeos de corta duración, actividades interactivas, animaciones y texto e imágenes con efectos interactivos.

Un enfoque para la creación de contenido online interactivo en las instituciones universitarias. Daniel Pérez-Berenguer y Jesús García-Molina.

Página 7 de 24 
Además, se ha elaborado un componente multimedia que facilita al docente la publicación y gestión de vídeos así como su enlace al elaborar el contenido de los cursos.

La gamificación es ampliamente reconocida como una técnica muy valiosa para mejorar la experiencia de aprendizaje y el rendimiento académico (Barata, G., Gama, S., Jorge, J. \& Gonçalves, D, 2013). Por ello, se ha creado un componente que permite al docente crear actividades de gamificación basadas en los diferentes tipos de juegos desarrollados seleccionando el periodo en el que serán llevadas a cabo. Por otro lado, el componente de evaluación facilita al docente la evaluación del aprendizaje del alumno proporcionándole diferentes opciones de evaluación y el componente de seguimiento se encarga de registrar los datos sobre el aprendizaje del alumno así como de su visualización y exportación. El componente de autenticación es el encargado de generar y proporcionar las claves de autenticación a cada docente que le permiten enlazar y desplegar en las plataformas e-learning los cursos elaborados.

Uno de los principales requisitos de la plataforma UPCTforma ha sido la integración de los contenidos creados con ella en cualquier plataforma LMS o MOOC existente que soporte los estándares de interoperabilidad SCORM o LTI. A continuación se comentan las dos estrategias que pueden seguir un desarrollador de un curso con UPCTforma para su integración en otra plataforma:

- Uso de SCORM. Las diferentes unidades son divididas en objetos de aprendizaje, auto-contenidos y reutilizables (SCOs, Sharable Content Objects). Se define la estructura del curso así como los recursos necesarios y su ruta mediante un fichero XML y finalmente son empaquetados en un fichero ZIP. Las rutas introducidas en el fichero XML pueden ser locales o remotas. Mediante el uso de rutas locales el contenido es desplegado sobre la plataforma LMS y mediante rutas remotas, al lanzar el SCO se crea un enlace sobre la plataforma web desarrollada. La primera opción no necesita de un servidor web pero la segunda opción presenta un mejor mantenimiento puesto que una modificación sobre el contenido de la plataforma web es visible en todas las plataformas e-learning que hayan enlazado el curso.

- Uso de LTI. El contenido se encuentra en la plataforma web desarrollada, enlazada desde la plataforma LMS o plataforma MOOC mediante el uso del framework TSUGI (TSUGI, 2016) que facilita la aplicación del estándar LTI. LTI está presente en plataformas MOOCs como edX o Coursera que no soportan SCORM.

A continuación, primero explicaremos en detalle el proceso ideado para crear contenidos con la plataforma UPCTforma, luego el formato Web definido para los contenidos y finalmente la estrategia de gamificación. La descripción de la arquitectura e implementación de UPCTforma queda fuera del ámbito de este artículo.

\section{4.- Proceso de producción de contenidos}

El proceso abarca todas las etapas de la producción del contenido docente interactivo, desde la definición de un guion del curso a partir del material disponible sobre dicho

Un enfoque para la creación de contenido online interactivo en las instituciones universitarias. Daniel Pérez-Berenguer y Jesús García-Molina. 
curso (normalmente, documentos en formato PDF, Word o PowerPoint) hasta la publicación del curso en una plataforma e-learning que cumpla con el estándar SCORM o LTI. En las etapas intervienen diferentes personas que juegan los siguientes roles:

- Jefe de Equipo: Es el encargado de planificar el orden de los proyectos de producción a realizar así como comprobar que los plazos previstos para el proyecto como para cada una de las fases se van cumpliendo. Debe dominar el resto de roles (excepto el de Docente) para, si es preciso, apoyar las actividades del equipo.

- Docente: Elabora un guion a partir del material disponible del curso, estructurando el contenido siguiendo las recomendaciones facilitadas por el guionista, proponiendo efectos interactivos y animaciones, indicando que actividades y donde introducirlas así como las evaluaciones a realizar. El contenido debe cumplir con todas las normas (referencias, derechos de imágenes, etc.) para poder llevar a cabo su publicación.

- Guionista: A partir del guion inicial suministrado por el docente, elabora un documento organizando dicho guion pensando en un diseño web.

- Desarrollador Web: Realiza el desarrollo web completo a partir del documento elaborado por el guionista en un determinado formato.

- Programador SCORM/LTI: Agrega la programación SCORM o LTI al código web que el equipo de desarrollo ha dejado en el servidor. Realiza las pruebas sobre la plataforma e-learning.

La Figura 1 representa el proceso por medio de un diagrama SPEM que muestra las etapas y flujo de ejecución. El lenguaje estándar SPEM (SPEM, 2008) también será usado para representar cada una de las etapas del proceso. Cabe destacar que en una etapa previa se forma al personal docente en la creación de contenidos y se les instruye en recomendaciones para crear contenidos didácticos. Además, reciben formación sobre el proceso que hemos definido, las plantillas disponibles y el manejo de la plataforma elearning que hemos creado. Los docentes usarán la plataforma para obtener información sobre el seguimiento de la actividad de aprendizaje por parte de los alumnos. El docente formará parte del grupo de trabajo durante todo el tiempo que dure el proyecto de creación de los contenidos. A continuación, se explica cada una de las siete etapas del proceso:

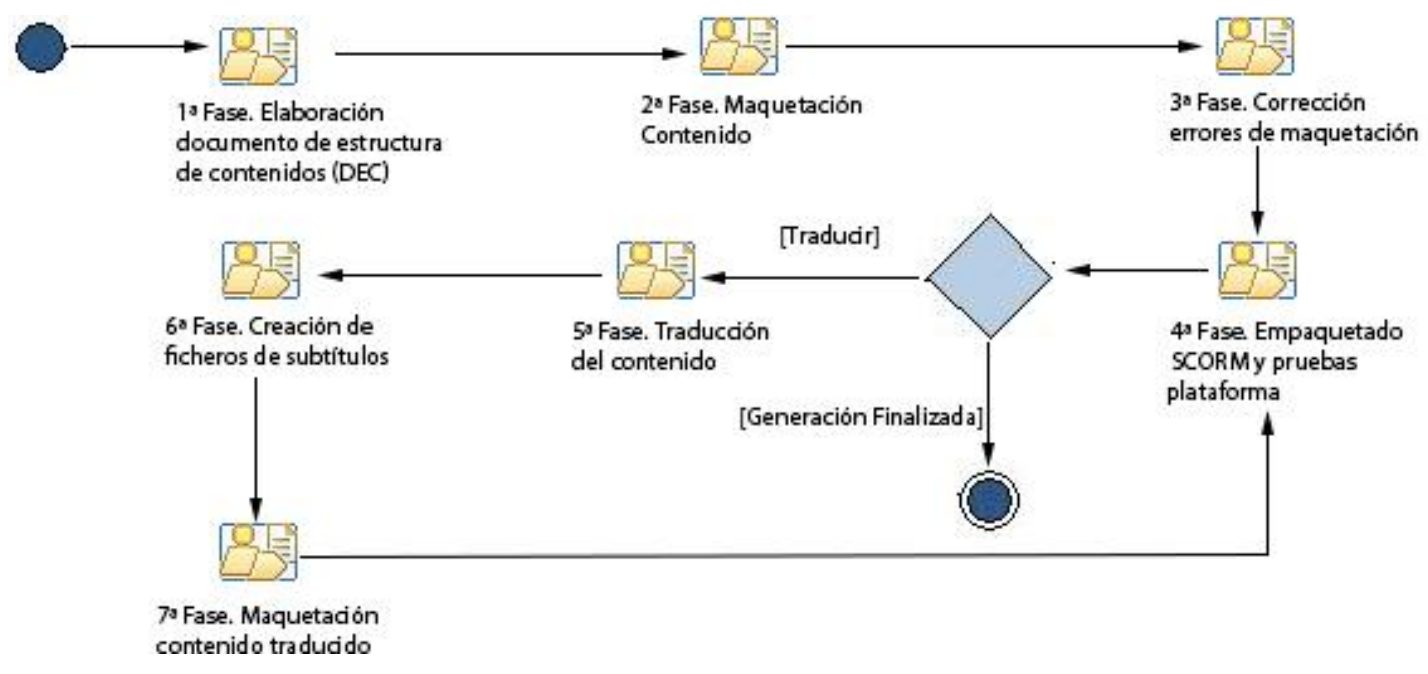

Un enfoque para la creación de contenido online interactivo en las instituciones universitarias. Daniel Pérez-Berenguer y Jesús García-Molina.

Página 9 de 24 
Figura 1. Fases en la generación de contenidos docentes interactivos.

\section{Fase 1. Elaboración del documento de estructura de contenidos}

Partiendo del guion inicial elaborado por el docente, el guionista elabora un documento PowerPoint (Documento de Estructura de Contenidos, DEC) que organiza dicho guion de acuerdo al banco de plantillas e imágenes de los que dispone. El guionista ayuda al docente a encontrar un diseño equilibrado en cuanto a contenido e imágenes, con ayuda a la navegación a través de elementos gráficos y/o textos explicativos, con elementos interactivos y/o animaciones que propicien la participación del alumno. Para ello, también se pueden incluir actividades que permitan afianzar los conocimientos (como por ejemplo de tipo test o de relacionar conceptos). Cada plantilla e imagen tiene asociado un identificador alfanumérico que el DEC usa para referenciarlos. Estos identificadores permiten posteriormente que el desarrollador web pueda realizar la maquetación. Una vez el diseño de los contenidos ha sido discutido con el docente, el guionista crea una primera versión del DEC que pasa al docente para su revisión. Se fijan reuniones hasta obtener una versión definitiva aceptada por el docente, la cual se envía al equipo de desarrollo web. La Figura 2 muestra el diagrama SPEM para esta etapa.

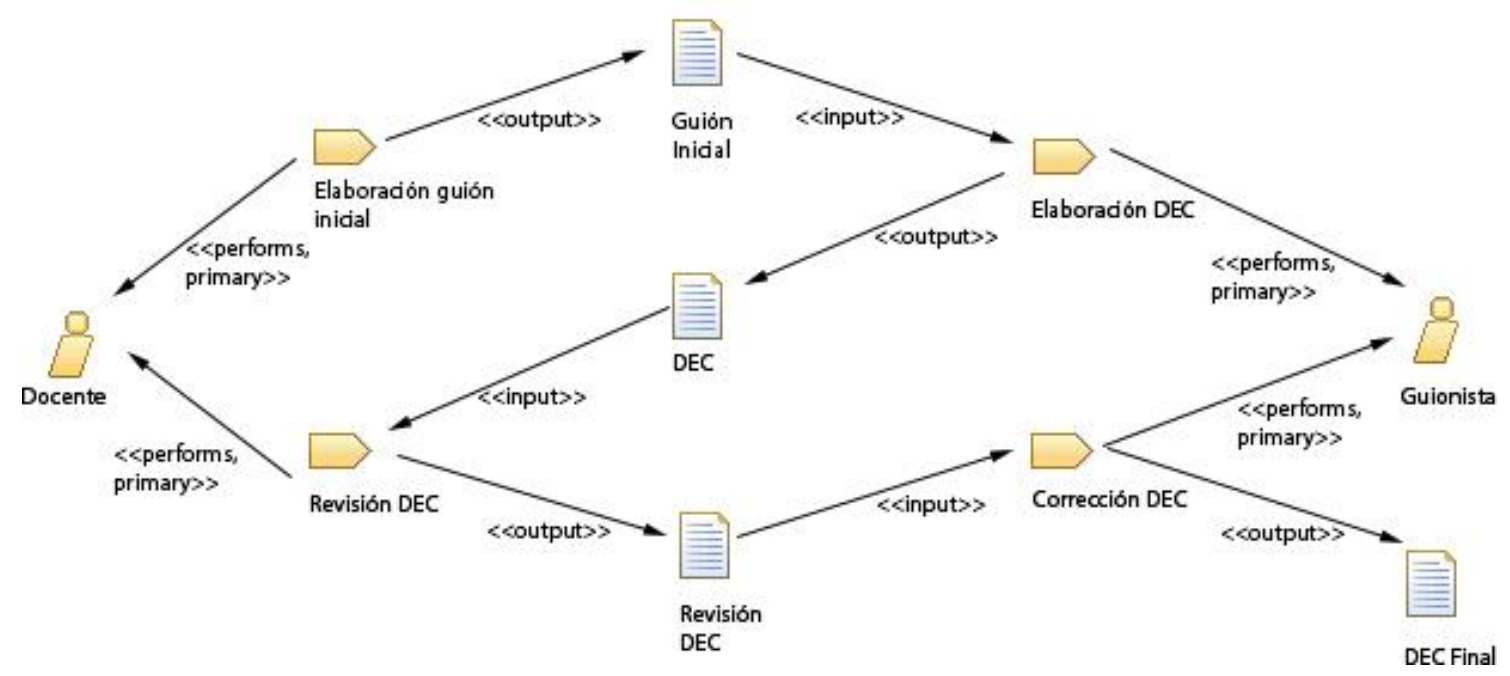

Figura 2. Primera fase del proceso.

\section{Fase 2. Maquetación del contenido}

A partir del DEC, el equipo de desarrollo web realiza la maquetación utilizando los bancos de plantillas e imágenes. El guion expresado en forma de documento DEC incluye toda la información necesaria para ello. El desarrollador web debe completar el código de cada plantilla usada para adecuarlo a un contexto particular. Para ello, deberá rellenar los "huecos" en el código de una plantilla con el texto o los identificadores de archivos de imágenes, vídeos o animaciones. Será necesario depurar cada uso de una plantilla para detectar errores como la duplicidad de un identificador de recurso o que la especificación de un recurso es correcta.

Un enfoque para la creación de contenido online interactivo en las instituciones universitarias. Daniel Pérez-Berenguer y Jesús García-Molina. 
Por otro lado, cabe destacar que las animaciones solicitadas por el guionista requieren una programación personalizada no basada en plantillas dado que suponen la animación de imágenes o texto ligados al contenido particular del curso que se está maquetando.

Una vez el equipo de desarrollo ha terminado la maquetación, publica el contenido en un servidor web de pruebas y le pasa la URL al guionista. Este realiza una primera revisión generando un documento de "revisión de maquetación" (DRM) que envía al equipo de desarrollo. En este documento se anotan los errores encontrados, localización del mismo (captura de pantalla) y acción a aplicar. Este proceso se repite hasta que el guionista da la conformidad a la maquetación al comprobar que todas las tareas del DRM han sido cumplimentadas. La Figura 3 muestra el diagrama SPEM para la segunda fase.

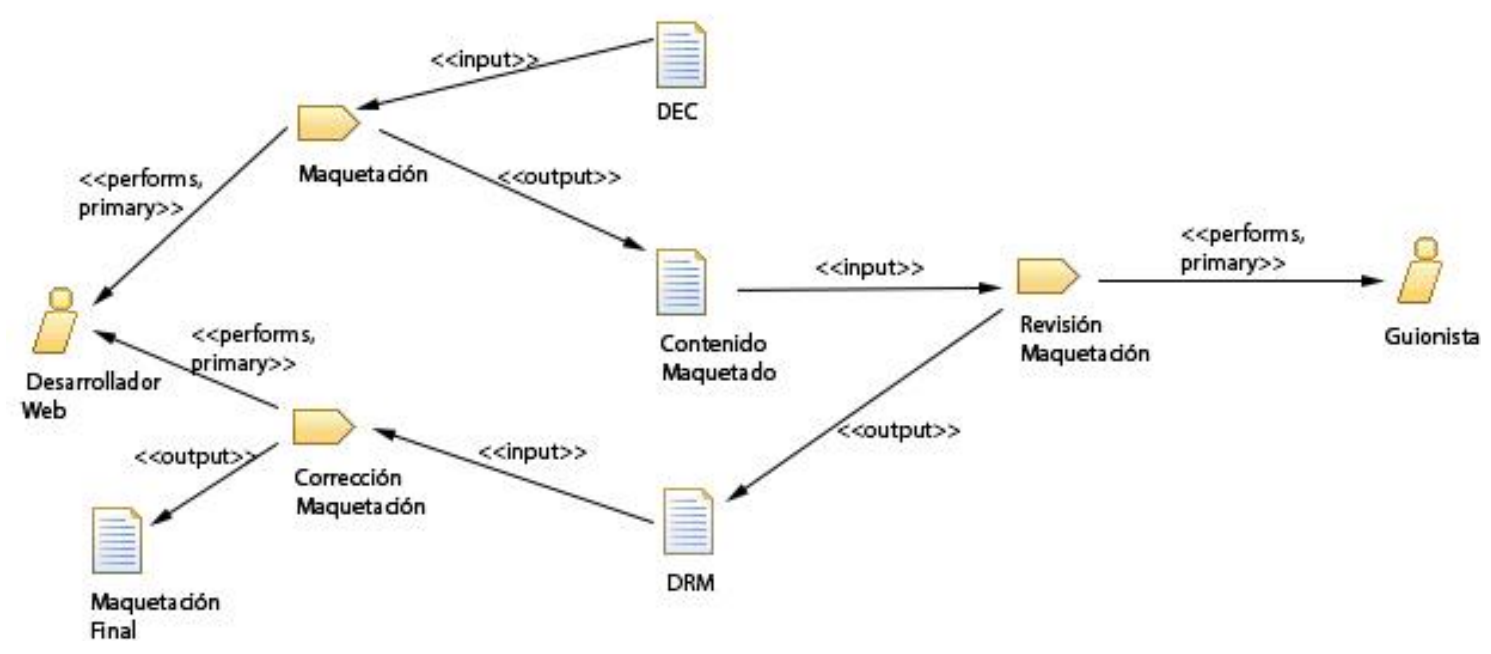

Figura 3. Segunda fase del proceso.

\section{Fase 3. Corrección de errores de maquetación}

El guionista suministra la URL del contenido maquetado al docente para su revisión. El docente sólo puede marcar errores de maquetación que se hayan producido en la segunda fase y que corresponden a aspectos que no son conformes al DEC. Una vez el docente realiza la revisión, el guionista prepara un nuevo documento de revisión de maquetación de acuerdo a los errores indicados por el docente. Este documento es enviado al equipo de desarrollo para realizar las correcciones sobre el contenido maquetado.

Conviene destacar que durante las tres primeras fases el docente sólo interacciona con el guionista en las diferentes tareas en las que participa. De esta forma se consigue una comunicación más fluida entre ambos roles, evitando errores y pérdidas de tiempo innecesarias. Una vez terminada esta fase, en el servidor web se encuentra el contenido maquetado revisado y aceptado por el docente. No se realizarán más revisiones ni por el guionista ni por el docente. La Figura 4 muestra el diagrama SPEM para esta etapa.

Un enfoque para la creación de contenido online interactivo en las instituciones universitarias. Daniel Pérez-Berenguer y Jesús García-Molina. 


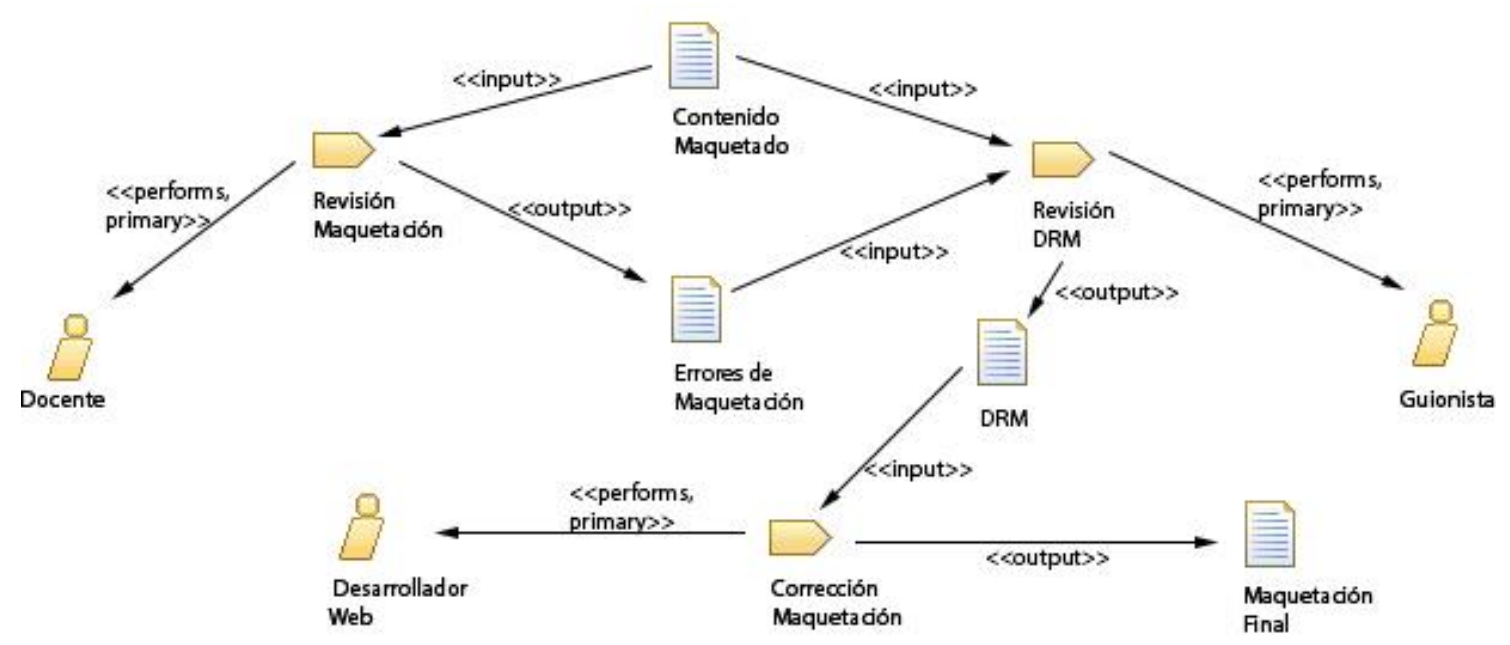

Figura 4. Tercera fase del proceso.

\section{Fase 4. Interoperabilidad con SCORM o LTI y pruebas de la plataforma}

El desarrollador de SCORM/LTI toma el contenido maquetado que se encuentra en el servidor Web y realiza su empaquetado o enlace según se elija el estándar SCORM o LTI, respectivamente. En el caso de usar SCORM, agrega las librerías JavaScript necesarias, crea el fichero XML (imsmanifest.xml) que define la estructura del contenido así como los recursos necesarios y su ruta. Por último, genera el fichero ZIP que empaqueta el contenido y sube este fichero a una plataforma e-learning de pruebas con el fin de comprobar que la plataforma realiza correctamente el seguimiento del curso, esto es, registra el progreso así como el tiempo empleado en cada unidad de aprendizaje. Si la elección es LTI, prepara el curso creado para ser accesible a través del framework TSUGI que implementa el estándar LTI. Además, se agregan unas librerías de desarrollo propio al curso que registran el aprendizaje del alumno (tiempos acumulados así como objetivos superados) dado que a diferencia de SCORM, LTI no define la forma de registrar esta información.

Una vez todas las pruebas han sido ejecutadas con éxito, el desarrollador SCORM/LTI sube definitivamente el fichero SCORM a la plataforma e-learning (Moodle en el caso de la UPCT, pero puede ser cualquier otra) o crea el enlace LTI, según corresponda, e informa al docente de la finalización. En caso de ser necesario se forma al docente en el uso de la plataforma para que pueda obtener la información sobre el seguimiento de la actividad de aprendizaje del alumno. La Figura 5 muestra el diagrama SPEM para la cuarta etapa del proceso.

Un enfoque para la creación de contenido online interactivo en las instituciones universitarias. Daniel Pérez-Berenguer y Jesús García-Molina. 


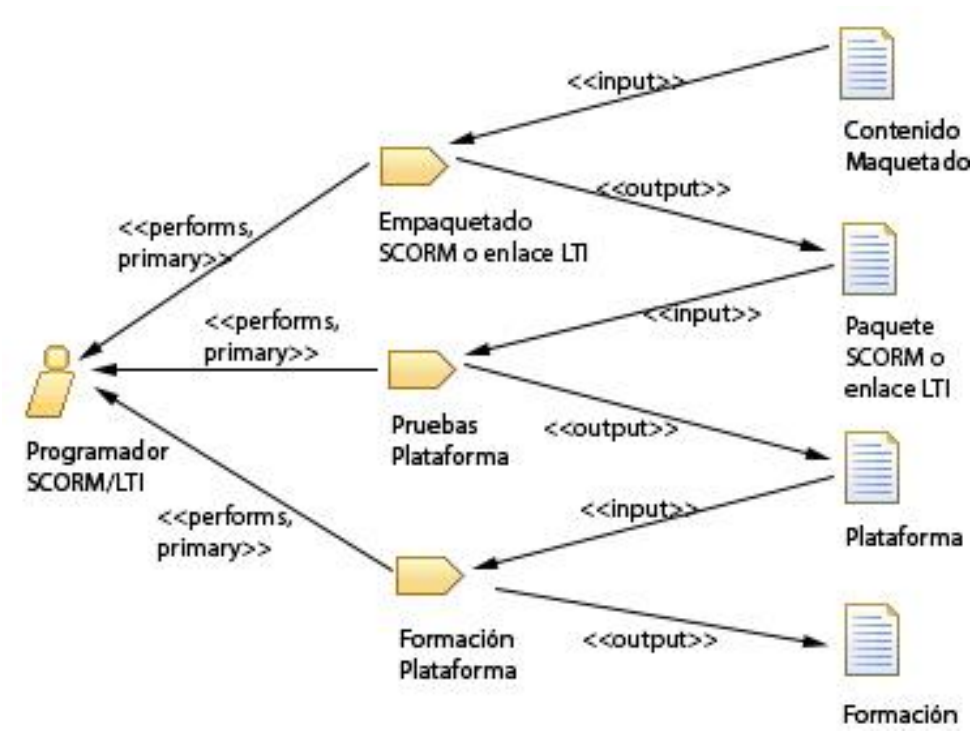

Figura 5. Cuarta fase del proceso.

En el caso de que los contenidos de un curso quieran ser traducidos a otros idiomas, el proceso finaliza con las tres etapas que explicamos a continuación.

\section{Fase 5. Traducción del contenido a diferentes idiomas (opcional)}

El guionista proporciona la URL del curso a un traductor. Éste traduce todos los textos, tanto los que están incrustados en el código HTML como los que forman parte de las ilustraciones o animaciones. Además, traduce los diferentes vídeos del curso para que puedan ser subtitulados. Las traducciones son entregadas en un documento Word al guionista.

\section{Fase 6. Creación de ficheros SRT de subtítulos (opcional)}

El guionista se encarga de generar los ficheros SRT de los subtítulos, anotando el momento de inicio y final así como el texto traducido que debe mostrarse durante ese intervalo.

\section{Fase 7. Maquetación del contenido traducido (opcional)}

El guionista suministra la traducción y los ficheros de subtítulos, solicitando al equipo de desarrollo web que produzcan un nuevo curso traducido (partiendo del original) y que el resultado sea depositado en una nueva URL del servidor web. También realiza una revisión que da lugar a un DRM (si procede) y que es suministrado al equipo de desarrollo web para realizar las correcciones de maquetación. Este proceso se repite hasta obtener la maquetación traducida definitiva. Una vez finalizada la maquetación del contenido traducido se vuelve a la fase 4 para el empaquetado en SCORM o LTI y posteriormente a la fase 5 si hay que traducirlo a otro idioma.

La Figura 6 muestra un ejemplo de un curso realizado siguiendo el proceso explicado y en la URL http://forma.upct.es/ se puede acceder a la plataforma e-learning utilizada en la UPCT donde se encuentra disponible un tema de dicho curso (material elaborado para la asignatura "Gestión de los Recursos Humanos" del Grado de Administración y

Un enfoque para la creación de contenido online interactivo en las instituciones universitarias. Daniel Pérez-Berenguer y Jesús García-Molina. 
Dirección de Empresas). Para acceder a la plataforma es necesario utilizar el nombre de usuario "usuario" y la contraseña "Usuario123\$".

\section{5.- Organización de los contenidos}

En esta sección describiremos el formato diseñado para la presentación Web de los contenidos de los cursos, así como el proceso de evaluación aplicado. En cada curso producido, las unidades de aprendizaje se ajustan al siguiente formato de presentación Web:

- Menú superior que nos permite acceder a cada una de las secciones de la unidad de aprendizaje, como se puede observar en la Figura 6. El desplazamiento hacia la sección se realiza mediante un scrolling.

- Cabecera con unos círculos que indican el nivel de progreso del alumno en cada sección, como muestra la Figura 7. El tamaño de los círculos es proporcional al número de objetivos establecidos en la sección asociada. Si se pulsa sobre el círculo nos lleva hacia la sección que controla.

- Secciones que engloban una parte del contenido docente de la unidad de aprendizaje. Cada sección se caracteriza por una imagen que completa todo el ancho de la pantalla y que contiene el título de la sección.

- Cada sección está compuesta por bloques de contenido que se distinguen el uno del otro por el color de fondo (se van alternado entre blanco y gris).

- Cada bloque contiene texto, imágenes, vídeos y animaciones interactivas.

- Información de ayuda que acompaña a todas las actividades y para orientar al alumno a la realización de las mismas.

- Un pie de página que cierra la maquetación.

Un enfoque para la creación de contenido online interactivo en las instituciones 


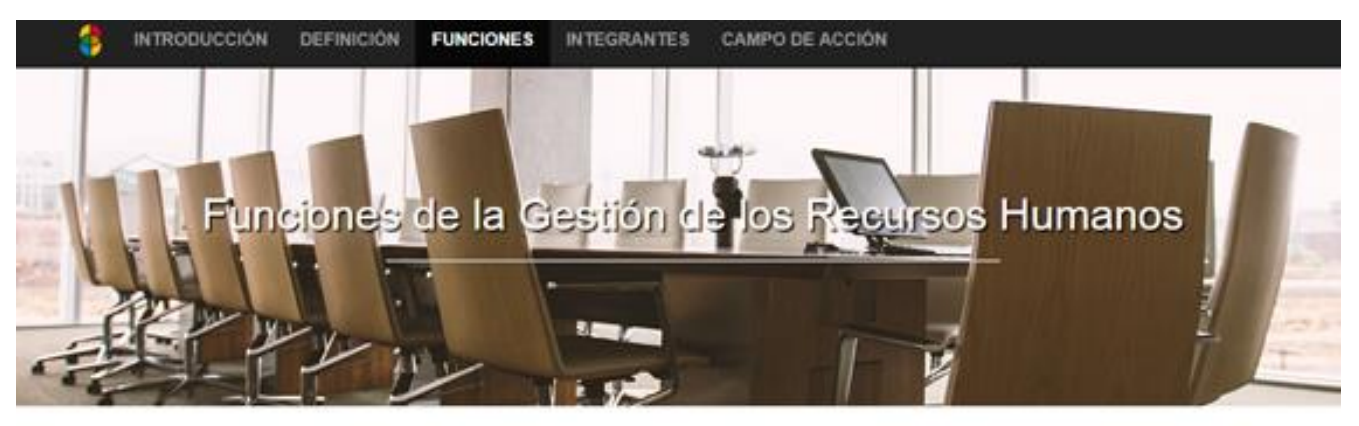

Segin los autores Byars $y$ Rue (1997) las funciones do la gestion de Recursos Humanos san aquellas tareas y deberes que deben cumplirse en todas las empresas, tanto en las grandes cocio en tas pequefas, para usi poder oblener y coordinar los Rocursos Humanos.

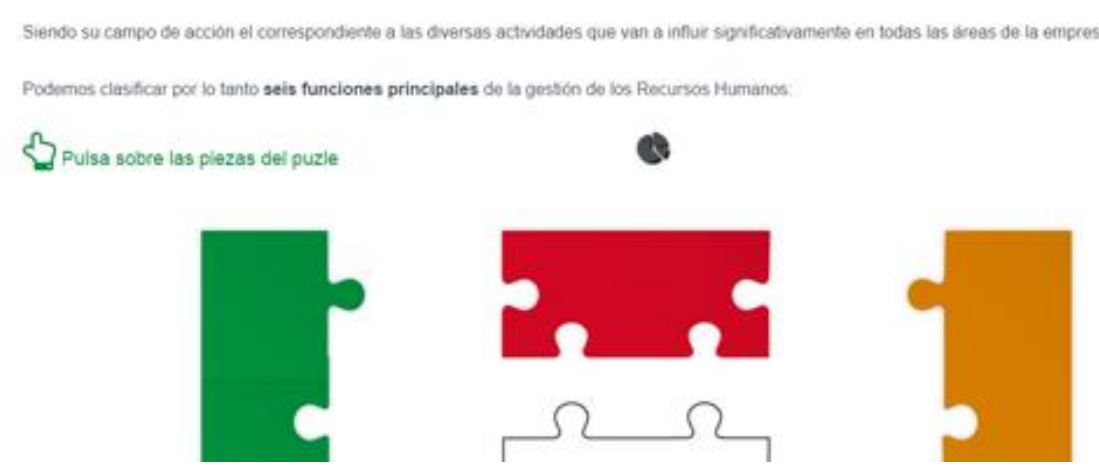

Figura 6. Curso “Gestión de los Recursos Humanos" de la UPCT

En cada bloque de contenido se fijan una serie de actividades que permiten comprobar que el alumno está realizando el curso. Estas actividades son objetivos SCORM u objetivos creados para LTI mediante librerías de desarrollo propio y están asociados a diferentes tipos de acciones como pulsar sobre un botón, situarse encima de una imagen o ver un vídeo. Conforme se van completando los objetivos se va aumentando el porcentaje sobre los círculos de la cabecera y se destaca el elemento asociado al objetivo sobre la página. Este elemento puede ser cualquier efecto que permita al alumno verificar que la actividad ha sido completada.

Los textos y las imágenes pueden presentar diferentes efectos, como por ejemplo, imágenes que al pulsarlas aparece un texto oculto, botones que abren ventanas modales con contenido, imágenes que al situarte encima muestran texto, o pestañas de contenido.

Cada vídeo incrustado en el desarrollo está asociado con un objetivo. Dicho objetivo se da por superado cuando se ha reproducido un porcentaje del vídeo a elección del docente. Se han realizados tres implementaciones que se detallan a continuación:

- Servidor interno de streaming.

- Vimeo ${ }^{15}$ como servidor de streaming.

- Vzaar ${ }^{16}$ como servidor de streaming. En esta implementación se decidió aumentar el nivel de seguridad en la reproducción de los vídeos utilizando el mecanismo de token de seguridad que proporciona Vzaar. El token de seguridad

\footnotetext{
15 https://vimeo.com/

${ }^{16} \mathrm{https}: / /$ vzaar.com/
}

Un enfoque para la creación de contenido online interactivo en las instituciones universitarias. Daniel Pérez-Berenguer y Jesús García-Molina. 
es creado por el propietario del vídeo a partir de la clave secreta compartida con Vzaar. Al solicitar el vídeo, Vzaar comprueba que el token de seguridad que le llega con la petición es válido sirviendo así el vídeo para su reproducción.
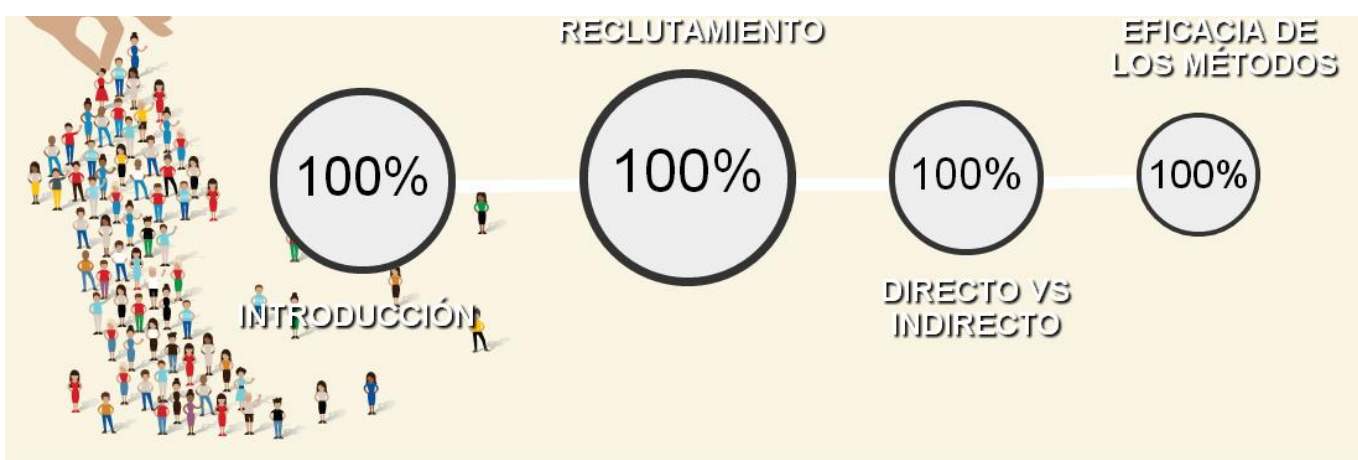

\section{RECLUTAMIENTO DE RECURSOS HUMANOS}

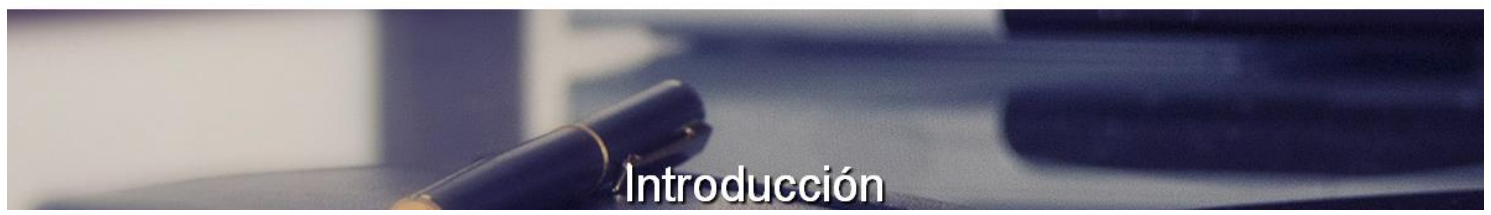

Figura 7. Cabecera del curso "Gestión de los Recursos Humanos"

Las animaciones interactivas se encuentran enlazadas a objetivos. Para superar el objetivo se tiene que cumplir con la lógica de la animación (como por ejemplo pulsar sobre todos los elementos interactivos). Un ejemplo de animación interactiva se puede ver en la Figura 8. Al pulsar sobre la primera pieza, sea cual sea, todas las piezas se mueven hasta juntarse y aparecen sobre ellas unos textos. A continuación, al pulsar sobre cada pieza aparece en el centro de la composición un texto que estaba oculto. Una vez pulsadas todas las piezas se activa el elemento gráfico, en este caso el gráfico circular situado en la parte superior central. Todas las animaciones se acompañan de unas instrucciones que ayudan al usuario a realizar las interacciones.

Un enfoque para la creación de contenido online interactivo en las instituciones universitarias. Daniel Pérez-Berenguer y Jesús García-Molina. 


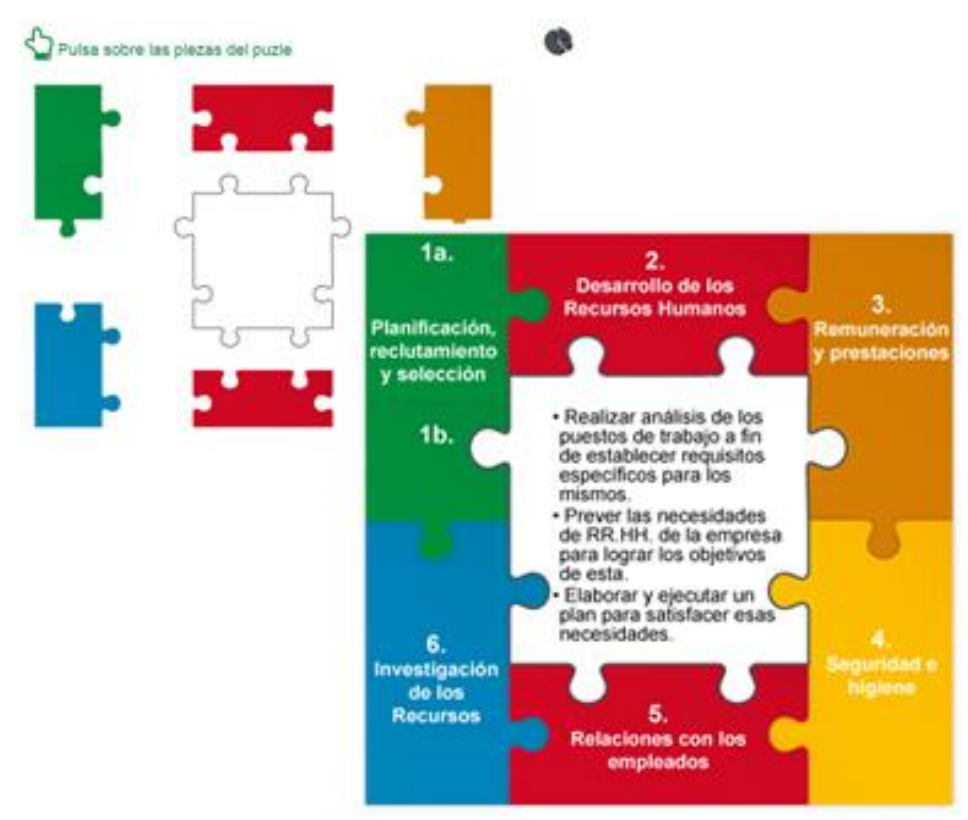

Figura 8. Animación interactiva del curso Gestión de los Recursos Humanos

Se ofrecen tres opciones de evaluación que serán aplicados a criterio del docente, y que pueden ser aplicadas de manera independiente:

- Evaluación Integrada en el Contenido. Se realiza una evaluación continuada mediante la inclusión de actividades integradas con el contenido y asociadas a objetivos que deben ser superados para completar la unidad de aprendizaje. En esta categoría se encuentran actividades de desplazamiento, preguntas de tipo test, visualización de vídeos, pulsar sobre imágenes para que aparezca texto que está oculto o interactuar con animaciones. El estado de estas actividades queda reflejado en la plataforma e-learning mediante la comunicación establecida entre el contenido y la plataforma a través de SCORM o LTI. El usuario puede ver el estado de las actividades a través de los círculos que se encuentran en la cabecera (indican el porcentaje de actividades superadas) así como a través del elemento gráfico que acompaña a cada actividad que es destacado en el caso de la superación. Cuando todos los objetivos de la unidad son superados, tanto con SCORM como con LTI, se envía a la plataforma e-learning la calificación que será integrada en el libro de calificaciones.

- Evaluación por Unidad de Aprendizaje. Se trata de una evaluación con preguntas tipo test multievaluadas. Son evaluaciones intermedias con repeticiones ilimitadas cuyo objetivo es que el alumno pueda probar su nivel de conocimientos. Se puede fijar un número de repeticiones determinado a petición del docente. Las preguntas se obtienen de un banco de preguntas y de forma aleatoria. Dado que esta evaluación permite múltiples intentos, en la plataforma se almacena la nota de uno de los intentos, que por regla general suele ser la de mayor puntación pero que puede ser cambiado a petición del docente.

- Evaluación Final. Se trata de una evaluación que se realiza al final del curso y que engloba todas las unidades de aprendizaje del mismo. Las preguntas de esta

Un enfoque para la creación de contenido online interactivo en las instituciones universitarias. Daniel Pérez-Berenguer y Jesús García-Molina. 
evaluación se obtienen de un banco de preguntas diferente que contiene preguntas de todas las unidades de aprendizaje. En este caso el número de intentos suele ser uno pero, al igual que en la opción anterior, es establecido a petición del docente.

\section{6.- Gamificación}

Mediante la inclusión de juegos en los métodos de enseñanza se pretende aumentar la motivación de los alumnos. Esta técnica recibe el nombre de "gamificación" y el interés por ella es creciente en los últimos años (Deterding, S., Dixon, D., Khaled R., \& Nacke L., 2011). Los juegos normalmente son usados para complementar los contenidos online de un curso aunque la gamificación puede ser puesta en práctica de manera independiente a la creación de contenidos digitales. La plataforma UPCTplay ${ }^{17}$ ha sido desarrollada para soportar la gamificación en nuestro enfoque de creación de contenidos para cursos online.

El docente puede seleccionar un juego, establecer las fechas de realización, comprobar el ranking, matricular a los alumnos en los juegos seleccionados, entre otras funcionalidades. Por otra parte, los alumnos pueden acceder a UPCTplay para participar en juegos con el fin de afianzar los conceptos de una asignatura. Una vez impartida la asignatura los alumnos disponen de un periodo mínimo de dos semanas para participar en los juegos creados por los docentes de dicha asignatura.

UPCTplay se ha implementado como una aplicación web que consta de los siguientes elementos:

- Página principal que explica qué es la gamificación y los beneficios de aplicarla en la docencia. Esta página contiene un formulario de autenticación para el docente y el alumno matriculado.

- Panel para el docente en la que un profesor puede:

- Dar de alta una actividad proporcionando la siguiente información: el juego que quiere utilizar, las fecha de inicio y fin, y el fichero con las preguntas que serán utilizadas durante el juego.

- Una vez creada la actividad, puede matricular alumnos en dicha actividad.

- Panel para el administrador de la plataforma a través del cual puede dar de alta a los docentes así como asignarles los juegos que puede utilizar.

- Panel para el alumno a través del cual puede acceder al juego y consultar la clasificación de los jugadores.

Se ha desarrollado un módulo que permite a los usuarios (docentes y alumnos) de la plataforma comunicarse a través de Telegram $^{18}$. Se escoge este sistema de comunicación como una manera más ágil de interactuar. Aun así, la comunicación se hace simultáneamente a través del correo electrónico y de Telegram.

\footnotetext{
${ }^{17}$ http://play.upct.es/

${ }^{18}$ https://telegram.org/
}

Un enfoque para la creación de contenido online interactivo en las instituciones universitarias. Daniel Pérez-Berenguer y Jesús García-Molina. 
Cuando un alumno es matriculado en un juego por un docente recibe un mensaje por Telegram y un correo electrónico informándole que ha sido dado de alta y que puede utilizar el juego de manera inmediata (se le adjunta la URL del juego). Se agregan diferentes avatares que el alumno escoge al entrar a la plataforma evitando el uso de fotografías personales.

Para probar UPCTplay se ha creado un primer juego, La Ruleta ${ }^{19}$, que consiste en un trivial de preguntas en el que los alumnos retan o son retados. Los ganadores de los retos obtienen puntos que van acumulando a lo largo del periodo establecido para jugar. Se elabora un ranking a partir de esta puntuación y en base a ese ranking los alumnos obtienen puntos extra para la asignatura. Una vez el alumno se autentica en la plataforma puede empezar a jugar. Al iniciar el juego se lanza un reto aleatorio contra alguno de los alumnos matriculados. El alumno retado recibe un Telegram y un e-mail y dispone de dos días para realizar el reto o se da por ganador al retador. En este tiempo deberá intentar contestar correctamente el máximo número de preguntas. La Figura 9 muestra la pantalla de inicio del juego. El alumno pulsa en el centro y la ruleta se mueve hasta que se selecciona un tema. Se escoge aleatoriamente una pregunta del tema y se le muestra al alumno para que responda en un tiempo limitado (por ejemplo 30 segundos). Se van sumando las preguntas acertadas y se comparan con las del jugador retado ganando el que más preguntas haya contestado correctamente. Por cada reto ganado se obtienen tres puntos, 1 punto por empate y 0 puntos para el jugador que pierde. Estos puntos se van acumulando conforme se van realizando retos. Se establece un número de retos máximo por jugador (por defecto 10) donde se cuenta tanto los retos iniciados como los recibidos. De esta manera se les dan las mismas posibilidades de juego a todos los alumnos incentivando la participación. El alumno podrá jugar durante el periodo establecido por el docente habilitando dos días extras en los que se pueden contestar los retos iniciados pero no se pueden iniciar más retos. A través de la plataforma web el alumno puede ver qué posición ocupa en el ranking. El ranking contiene el número de partidas jugadas, las ganadas, empatadas y perdidas, posición, etc. Una vez finalizada la actividad se obtiene una clasificación de los alumnos que han participado en la actividad. El docente comprueba el ranking y otorga puntos extra para la asignatura en función de las posiciones.

Actualmente se están desarrollando otros juegos de manera que se construya un banco de juegos que cubran la diversidad de asignaturas impartidas en la UPCT. Además se pretende enlazar la plataforma con el servidor de autenticación de la UPCT (servidor CAS) evitando el registro manual de los alumnos.

\footnotetext{
${ }^{19}$ http://play.upct.es/index.php/la-ruleta.html
}

Un enfoque para la creación de contenido online interactivo en las instituciones universitarias. Daniel Pérez-Berenguer y Jesús García-Molina. 


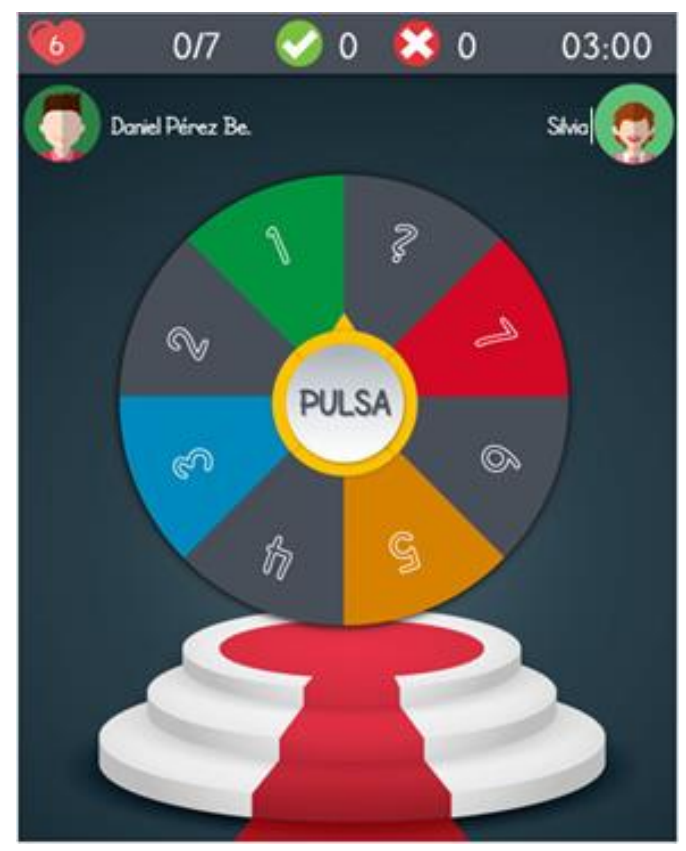

Figura 9. La Ruleta, juego de preguntas y respuestas elaborado por el CPCD/UPCT

\section{7.- Conclusiones}

Uno de los grandes retos a los que se enfrentan las universidades de todo el mundo es la incorporación de contenidos virtuales online en su formación, con el fin de aplicar metodologías como el aprendizaje mixto o el aula invertida. Esto supone un coste muy elevado y será preciso idear soluciones que permitan realizar esta transición de forma eficaz y eficiente. En este artículo se ha presentado una iniciativa en este sentido que se está llevando a cabo en la UPCT.

Se ha descrito una estrategia para la generación de contenidos virtuales online a partir del material creado por los docentes en el marco de una enseñanza basada en técnicas tradicionales (por ejemplo, documentos PDF y presentaciones PPT). Los contenidos se crean mediante un proceso que implica siete etapas (las tres últimas cuando es necesario una traducción a otro idioma) y varios roles, y que es soportado por una infraestructura software específicamente creada para soportar este proceso. El contenido se elabora de acuerdo a un formato bien definido que incorpora animaciones interactivas o efectos avanzados sobre el texto o imágenes. Para conseguir independencia con respecto a la plataforma LMS, se ha utilizado SCORM y LTI. Mediante SCORM los contenidos se despliegan en la plataforma LMS o, al igual que en el caso de LTI, se enlaza la plataforma desarrollada con la plataforma LMS. Esto, además, proporciona al docente información sobre el seguimiento del aprendizaje del alumno tal como objetivos superados o tiempo invertido en las unidades de aprendizaje. La infraestructura que soporta la creación de contenidos también incluye una plataforma de gamification que permite a los docentes crear actividades basadas en juegos y a los alumnos participar en ellas, y realiza un seguimiento de la puntuación alcanzada.

Esta estrategia es aplicable para migrar asignaturas tradicionales a nuevas metodologías basada en contenidos virtuales y online, o también para crear MOOC. Por otra parte,

Un enfoque para la creación de contenido online interactivo en las instituciones universitarias. Daniel Pérez-Berenguer y Jesús García-Molina.

Página 20 de 24 
estos cursos pueden ser aplicados en diferentes entornos, por supuesto en las instituciones universitarias pero también por los departamentos de recursos humanos para proporcionar una formación continuada a su personal y en general, para cualquier empresa que quiera dar formación.

De momento se ha probado en la elaboración de varios cursos, tanto para asignaturas regladas como cursos de formación para una empresa con sedes en diferentes países. Se ha producido un curso para la asignatura "Gestión de los Recursos Humanos" del Grado de Administración y Dirección de Empresas, al cual corresponden los ejemplos presentados en este artículo. También se han desarrollado cursos como parte del Proyecto Europeo ACADIA (African Center for Applicative Development \& Innovation in Agribusiness) donde la UPCT imparte docencia online a universidades de Kenya y Uganda. Finalmente, se ha desarrollado un paquete de cursos para una de las mayores empresas nacionales de desarrollo de software. A continuación señalamos algunas de las principales conclusiones extraídas de esta experiencia:

- Los docentes valoran positivamente su participación en el proceso, en particular que sólo deben tratar con el guionista y que se les permite proporcionar feedback sobre el diseño inicial del curso, así como que son aislados de detalles de implementación.

- Los docentes consideran que el tiempo dedicado al diseño del guion y la corrección de errores es muy inferior a lo que sería tener que crear ellos los contenidos.

- Los docentes señalan que la plataforma permite crear contenidos con una imagen muy profesional y muy propicia para combinarla con la metodología de aula invertida.

- El formato de cursos ha resultado muy atractivo para los alumnos y esto ha fomentado su participación. Cabe destacar que tras la presentación de la asignatura de "Gestión de los Recursos Humanos", la plataforma registró que ese mismo día los alumnos accedieron acumulando tiempos de aprendizaje que en algunos casos alcanzaban cuarenta y cinco minutos.

- El banco de plantillas reduce significativamente el tiempo de implementación del desarrollador web.

- Las características con los que son producidos los cursos hacen que su mantenimiento sea menos costoso que las unidades de aprendizaje basadas únicamente en vídeo.

- La información proporcionada sobre el seguimiento del proceso de aprendizaje del alumno permite al docente aplicar medidas para reconducir la actividad del alumno. Así, el docente puede detectar un abandono o desmotivación tras el análisis de la información que registra la plataforma como la fecha del último acceso, el tiempo que viene empleando en realizar las unidades de aprendizaje o los objetivos superados y aplicar medidas que puedan reconducir esta situación como la incorporación de material complementario que permita afianzar conceptos.

Un enfoque para la creación de contenido online interactivo en las instituciones universitarias. Daniel Pérez-Berenguer y Jesús García-Molina. 
- La incorporación del juego ha favorecido la preparación del examen de la asignatura: aprender jugando.

- El uso de tecnologías como HTML5, una alternativa a los cursos que actualmente se venían desarrollando en Flash Player, ofrece una mayor compatibilidad en dispositivos y navegadores.

En relación al trabajo futuro, se pretende una mayor automatización del proceso desarrollado para la creación de contenidos docentes interactivos aplicando técnicas de la Ingeniería del Software Dirigida por Modelos (García-Molina et al., 2013). Se pretende abordar el desarrollo del contenido por parte del docente y/o guionista sin la intervención del desarrollador web. El docente y/o guionista tendrían a su disposición un lenguaje específico del dominio (DSL) que permitiría expresar los guiones (documentos DEC). Por otro lado, el desarrollador web se encargaría de enriquecer la infraestructura con nuevas plantillas, con nuevos efectos, con formas de estructuración del contenido. El objetivo por tanto, es poder abordar esta actividad de una forma sistemática con un sistema que proporcione los medios necesarios para que el docente y/o guionista la puedan desarrollar de una manera eficaz y eficiente.

Presentación del artículo: 22 de mayo de 2016 Fecha de aprobación: 20 de julio de 2016 Fecha de publicación: 15 de noviembre de 2016

Pérez-Berenguer, D., y García-Molina, J. (2016). Un enfoque para la creación de contenido online interactivo en las instituciones universitarias. RED. Revista de Educación a Distancia, 51(X). Consultado el (dd/mm/aaaa) en

\section{Bibliografía}

Advanced Distributed Learning. (2016). SCORM Overview. Recuperado de https://www.adlnet.gov/adl-research/scorm/.

Barata, G., Gama, S., Jorge, J., y Gonçalves, D. (2013). Engaging engineering students with gamification. En Games and Virtual Worlds for Serious Applications (VSGAMES), 2013 5th International Conference. IEEE, Poole, Bournemouth, UK, 1-8.

Berrocoso, J. V. (2014). MOOC: una visión crítica desde las ciencias de la educación. Profesorado: Revista de curriculum y formación del profesorado, 18(1), 93-111.

Boneu, J. M. (2007). Plataformas abiertas de e-learning para el soporte de contenidos educativos abiertos. RUSC. Universities and Knowledge Society Journal, 4(1), 3647.

Castaño, C. y Cabero, J. (2013). Enseñar y aprender en entornos M-Learning. Madrid: Editorial Síntesis.

Daradoumis, T., Bassi, R., Xhafa, F., y Caballé, S. (2013). A review on massive elearning (MOOC) design, delivery and assessment. En P2P, Parallel, Grid, Cloud

Un enfoque para la creación de contenido online interactivo en las instituciones universitarias. Daniel Pérez-Berenguer y Jesús García-Molina.

Página 22 de 24 
and Internet Computing (3PGCIC), 2013 Eighth International Conference. IEEE, Compiegne, Francia, 208-213.

Deterding, S., Dixon, D., Khaled, R., y Nacke, L. (2011). From game design elements to gamefulness: defining gamification. En Proceedings of the 15th international academic MindTrek conference: Envisioning future media environments. ACM, New York, NY, USA, 9-15.

Gibbs, A. L. (2014). Experiences teaching an introductory statistics MOOC. En Proceedings of the ninth international conference on teaching statistics (ICOTS9). IASE, Flagstaff, Arizona, USA.

Glance, D. G., Forsey, M., y Riley, M. (2013). The pedagogical foundations of massive open online courses. First Monday, 18(5).

Guo, P. J., Kim, J., \& Rubin, R. (2014). How video production affects student engagement: An empirical study of mooc videos. En Proceedings of the first ACM conference on Learning@ scale conference. ACM, Atlanta, Georgia, USA, 41-50.

Hansch, A., Hillers, L., McConachie, K., Newman, C., Schildhauer, T., y Schmidt, P. (2015). Video and online learning: Critical reflections and findings from the field. HIIG Discussion Paper Series No. 2015-02.

IEEE LTSC. (2016). Institute for Electrical and Electronic Engineers Learning Technology - Standards Committee. Recuperado de http://ieeeltsc.org/.

IMS Global Learning Consortium. (2016). IMS Certified Product Directory. Recuperado de https://www.imsglobal.org/cc/statuschart.cfm

IMS Global Consortium. (2016). IMS Global Learning Consortium. Recuperado de http://www.imsglobal.org.

IMS Global Consortium. (2016). Learning Tools Interoperability, Version 1.0 Public Draft Specification. Recuperado de http://www.imsglobal.org/specs/ltimemv1p0

Instituto Nacional de Estadística. (2016). Encuesta sobre equipamiento y uso de tecnologías de información y comunicación en los hogares 2015. Recuperado de http://www.ine.es/.

Méndez García, C. (2013). Diseño e implementación de cursos abiertos masivos en línea (MOOC): expectativas y consideraciones prácticas. RED. Revista de Educación a Distancia, 39(4).

Molina, J. G., Rubio, F. O. G., Pelechano, V., Vallecillo, A., Vara, J. M., y VicenteChicote, C. (2013). Desarrollo de software dirigido por modelos: conceptos, métodos y herramientas. Editorial: RA-MA.

Object Management Group. (2016). Software \& Systems Process Engineering Metamodel Specification (SPEM). Recuperado de http://www.omg.org/spec/SPEM/2.0/

Open Education Europa. (2016). Open Education Scoreboard. Recuperado de http://www.openeducationeuropa.eu/es/european_scoreboard_moocs.

Peco, P. P., y Luján-Mora, S. (2013). Architecture of a MOOC based on CourseBuilder. En Information Technology Based Higher Education and Training (ITHET), 2013 International Conference. IEEE, La Rioja, Logroño, España, 1-8.

Un enfoque para la creación de contenido online interactivo en las instituciones universitarias. Daniel Pérez-Berenguer y Jesús García-Molina.

Página 23 de 24 
Pereira, J., Sanz-Santamaría, S., y Gutiérrez, J. (2015). Comparativa técnica y prospectiva de las principales plataformas MOOC de código abierto. RED. Revista de Educación a Distancia, 44(6).

Reich, J. (2015). Rebooting MOOC research. Science, 347(6217), 34-35.

Severance, C. (2016). TSUGI. A Framework for Building Learning Tools. Recuperado de http://tsugi.org/

Shah, D. (2014). Online courses raise their game: A review of MOOC stats and trends in 2014. Class Central.

Taneja, S., y Goel, A. (2014). MOOC providers and their strategies.International Journal of Computer Science and Mobile Computing, 3(5), 222-228.

Tsichritzis, D. (1999). Reengineering the university. Communications of the ACM, 42(6), 93-100.

Zapata-Ros, M. (2014). Los MOOC en la crisis de la Educación Universitaria: Docencia, diseño y aprendizaje. Amazon. 